\title{
Fracture and wear of the Sn11Sb5.5Cu Babbitt after equal-channel angular pressing
}

\author{
A. Kh. Valeeva ${ }^{1,2, \dagger}$, I.Sh. Valeev ${ }^{1,2}$, A. Kh. Akhunova ${ }^{1}$ \\ †valeevs@mail.ru \\ ${ }^{1}$ Institute for Metals Superplasticity Problems of RAS, 39 Khalturin str., Ufa, 450001, Russia \\ ${ }^{2}$ Bashkir State University, 32 Zaki Validi str., Ufa, 450076, Russia
}

A computer simulation and experimental study of the $\mathrm{Sn} 11 \mathrm{Sb} 5.5 \mathrm{Cu}$ Babbitt rods deformation by equal-channel angular pressing (ECAP) was carried out. The material was studied in two structural states. The first one (state $I$ ) produced by conventional crystallization during casting is characterized by large particles of the intermetallic $\beta$ - and $\eta$ - phases. In the second state (state II) produced by fast crystallization, the material contained small particles. ECAP processing was performed in a die with vertical and horizontal channels intersecting at a right angle, with pressure imposed by a punch located in the vertical channel of the die. On the basis of the computer simulation of the process by means of the DEFORM-2D software, the deformation speed providing the lowest damage of the workpieces was selected. The wear was determined by measuring the weight loss of the sample due to friction. The dependence of the Babbit wear in state $I$ has two clearly distinguished stages of running-in and steady-state wear. The wear of the samples in state II shows that the produced uniform distribution of intermetallic particles in the matrix phase leads to the absence of the running-in stage during wear. Severe plastic deformation (SPD) processing by ECAP leads to the dispersion of intermetallic phases particles and the weakening of the adhesive bond between the particles and the matrix. In state $I$, the refinement of large intermetallic particles causes a decline in wear. In state $I I$, after ECAP, the adhesion to the matrix weakens, and the softening of intermetallic particles occurs, which causes an increase in wear. Thus, SPD processing is not an efficient method for improving the tribological characteristics of the Sn11Sb5.5Cu Babbitt. In this case, the methods for producing a fine-grained structure, based on the variation of the crystallization rate during casting, are more effective and less costly.

Keywords: Sn11Sb5.5Cu Babbitt, equal-channel angular pressing (ECAP), wear, computer simulation.

\section{Introduction}

As a material for plain bearings for many large-size equipment units (for example, hydroelectric power plant turbines), Babbitt alloys having high tribological properties are traditionally used $[1,2]$. The structure of the hightin Babbitt Sn11Sb5.5Cu is composed of three phases: the $\alpha$-phase, which is a solid solution of antimony and copper in tin, and the particles of intermetallic phases - the $\beta$-phase, represented by SnSb crystals with hexagonal and rhombohedral lattices, and the $\eta$-phase, consisting of small $\mathrm{Cu}_{6} \mathrm{Sn}_{5}$ particles [3]. Such a structure fully corresponds to the Charpy rule, which says that a material with high antifriction properties should consist of a soft ductile base ensuring a good running-in ability, and large solid inclusions of the second phase, forming a strong frame that increases the loadbearing capacity of the alloy's surface and contributes to a reduction in the friction coefficient [4,7]. However, there are some papers [4-12] demonstrating that the homogeneous fine-grained structure of materials with ultradispersed second-phase particles, not corresponding to the Charpy rule, is able to provide high tribological and other physicomechanical properties. The studies conducted earlier by the authors of this paper [11-14] show that it is possible to produce a microstructure with a uniform distribution of the fine particles of intermetallic phases by means of varying the crystallization rate during the casting of the $\mathrm{Sn} 11 \mathrm{Sb} 5.5 \mathrm{Cu}$ Babbitt, or by means of applying pressure on the crystallizing material.

An efficient way to produce an ultrafine-grained structure in a material is severe plastic deformation (SPD) [15-17]. In addition, it enables modifying the sizes of secondphase particles and controlling their distribution [18]. For example, the study of the effect of equal-channel angular pressing (ECAP) on the microstructure and tribological characteristics of the $\mathrm{Sn} 11 \mathrm{Sb} 5.5 \mathrm{Cu}$ Babbitt $[7,8]$ revealed a noticeable, approximately by a factor of 1.6 , increase in the wear intensity of the Babbitt in the dry-friction regime, which is attributed to the accumulation of defects in the process of SPD. At the same time, a significant (as large as two-fold) decrease in the friction coefficient during friction with a lubricant was observed, which can be attributed to the formation, on the surface of the deformed Babbitt, of residual porosity which contributes to a better retention of the lubricant in the boundary-friction regime. High-pressure torsion [19] leads to the formation of a submicrocrystalline structure in the matrix $\alpha$-phase of the Sn11Sb5.5Cu Babbitt, as well as to a considerable refinement and spheroidization of the particles of intermetallic phases, accompanied by a significant increase in microhardness. Nevertheless, there are 
still unexplained issues related to the effect of SPD processing on the distribution and morphology of intermetallic particles in the matrix phase of the $\mathrm{Sn} 11 \mathrm{Sb} 5.5 \mathrm{Cu}$ Babbitt, as well as its wear under boundary friction.

The present paper deals with revealing the effect of ECAP processing on the size and distribution of intermetallic particles in the $\mathrm{Sn} 11 \mathrm{Sb} 5.5 \mathrm{Cu}$ Babbitt, and on its fracture and wear, by means of a full-scale experiment and computer simulation.

\section{Materials and methods}

As the material for the study, we selected the $\mathrm{Sn} 11 \mathrm{Sb} 5.5 \mathrm{Cu}$ Babbitt $(11 \% \mathrm{Sb}, 5.5 \% \mathrm{Cu}$, the rest is $\mathrm{Sn})$ produced by conventional casting in a chill mold at different crystallization rates [20]. An increase in the crystallization rate as a result of cooling in water enabled varying the samples microstructure.

ECAP processing was performed in a die with vertical and horizontal channels intersecting at a right angle, with pressure imposed by a punch located in the vertical channel of the die. A rod with a square cross section of $9.7 \times 9.7 \mathrm{~mm}$ and a length of $60.0 \mathrm{~mm}$ was subjected to deformation at room temperature.

The punch movement rate during the ECAP processing, ensuring the minimum fracture of the sample, was determined by computer simulation using the DEFORM-2D software. We built a model of the above-described die-set and sample. We assigned the properties of an absolutely rigid body to the punch and the die. The rod material was considered ductile, and its behavior was described by the experimental curves obtained during the upsetting of the Sn11Sb5.5Cu Babbitt samples at room temperature [20]. The contact conditions at the «rod-die» and «rod-punch» boundaries were described by Siebel's friction model [21]. The value of the friction coefficient was accepted as 0.01 . The body subjected to deformation was divided into 20-node isoparametric finite elements with a quadratic approximation of the displacement field. The number of elements was 5200 . We examined the ECAP process at three rates of punch displacement: $0.1 \mathrm{~mm} / \mathrm{min}, 1 \mathrm{~mm} / \mathrm{min}$ and $5 \mathrm{~mm} / \mathrm{min}$.

The wear of the samples was determined from the loss of their mass as a result of friction. The samples having an identical area with a radius of the working surface equal to $25 \mathrm{~mm}$ were preliminarily ground in to fit the counterbody represented by a disk on an SMTs-2 friction machine via the shoe-on-disk scheme. The disk with a diameter of $50 \mathrm{~mm}$ and a width of $12 \mathrm{~mm}$ was made of the $37 \mathrm{Cr} 4$ steel. The frequency of disk rotation during the wear tests was $300 \mathrm{rev} / \mathrm{min}$. The load on the sample during the wear tests was equal to $P=321.7 \mathrm{~N}$, which corresponded to the value of pressure on the contact surface equal to $p=5.3 \mathrm{MPa}$. On the basis of the results of preliminary tests, we found the friction path before weighing, $L_{p r(i)}=31.4 \mathrm{~m}$, and the friction path during steadystate wear, $L=1000 \mathrm{~m}$. Normally, plain bearings operate under the conditions of hydrodynamic lubrication where there is a thick separating layer of oil between the shaft and the half bearing. However, during the period of starting and at the stage of running-in the regime of boundary friction may take place, which is characterized by a more intensive wear. Therefore the wear was realized in the regime of boundary friction, where the disk was lubricated with the Shell CORENA P 150 compressor oil prior to each test. The samples were weighed on an ALC210d4 analytical balance with an accuracy of $10^{-4} \mathrm{~g}$. Three samples were tested for each state.

In order to reveal the Babbitt's structure, the samples were subjected to chemical etching with a solution of nitric and acetic acids in glycerine [22]. Study by optical metallography was performed on an Axiovert-100A microscope, using the KSLite software for image processing. To get a better understanding of the microstructural changes, the Vickers microhardness of the central portion of the samples was measured on the same microscope, using an MHT10 attachment, under an indenter load of $1.0 \mathrm{~N}$. Tens of measurements were made for each state, and the coefficient of measurement variation did not exceed $5 \%$.

\section{Results and discussion}

The variation of the cooling rate during the crystallization of the cast $\mathrm{Sn} 11 \mathrm{Sb} 5.5 \mathrm{Cu}$ Babbitt enables producing different initial microstructures in samples [20]. We studied the material in two structural states. During conventional crystallization (state $I$ ) there form large cubic particles of the $\beta$-phase $\mathrm{SnSb}$ with a size of $100-200 \mu \mathrm{m}$ and the $\eta$-phase in the shape of large stars - connection needles $\mathrm{Cu}_{6} \mathrm{Sn}_{5}$, non-uniformly distributed in the matrix $a$-phase. Rapid crystallization during water cooling (state $I I$ ) leads to a reduction in the size of the $\beta$-phase particles by an order of magnitude (down to $10-20 \mu \mathrm{m}$ ) and the formation of conglomerates consisting of 3-4 particles. The needles of the $\eta$-phase do not grow yet and remain small globular particles. Both intermetallic phases are located in the matrix in a relatively uniform manner.

The dependencies of the stress-strain state (SSS) parameters, namely, the stress state index $\sigma_{1} / \sigma_{i}$, the accumulated strain intensity index $\varepsilon_{i}$ and the scalar parameter of damage, $\omega$, at a material point adjacent to the internal angle of the die in the middle of the process, on the punch movement rate obtained by computer sumulation are shown in Fig. 1.

It can be seen that the largest values of the scalar parameter of damage and the stress state index, corresponding to a severe fracture of a sample, are observed at a low deformation speed $(0.1 \mathrm{~mm} / \mathrm{min})$. Apparently, this is related to the low ductility of the material under consideration. The smallest values of the stress state index and the scalar parameter of damage are ensured when the punch movement rate is $1 \mathrm{~mm} / \mathrm{min}$, hence this rate was selected for performing a full-scale experiment. From the results of the computer simulation, it is also possible to assume a less intensive wear of the samples with large intermetallic particles (state $I$ ) - the values of the considered quantities for such samples are smaller by about $15-20 \%$.

The microstructure of the samples from the $\mathrm{Sn} 11 \mathrm{Sb} 5.5 \mathrm{Cu}$ Babbitt after ECAP processing is shown in Fig. 2.

Study by optical microscopy reveals the cracking and fracture of the $\beta$-phase particles occurring after ECAP in the sample in state $I$. The $\eta$-phase needles acquire a globular shape and a stitch-like arrangement (Fig. 2a). In the sample in state $I I$, the groups of the $\beta$-phase particles, formed during 


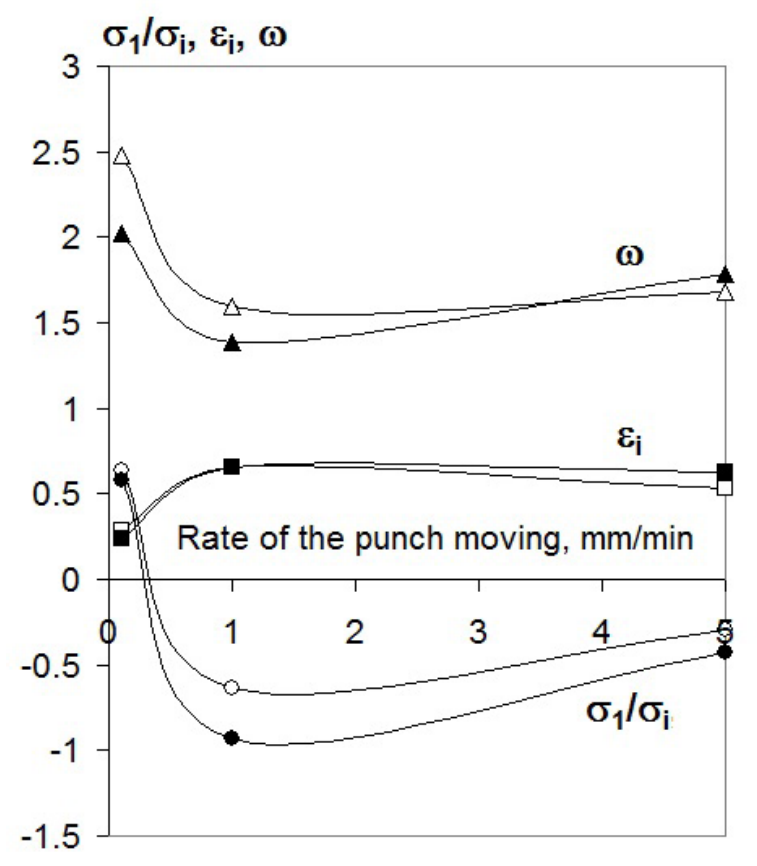

Fig. 1. Dependencies of the stress-strain state parameters on the rate of punch movement for different sizes of intermetallic particles. Light symbols denote small $\beta$-phase particles with a size of $50 \mu \mathrm{m}$, and dark symbols denote large particles $(250 \mu \mathrm{m})$.
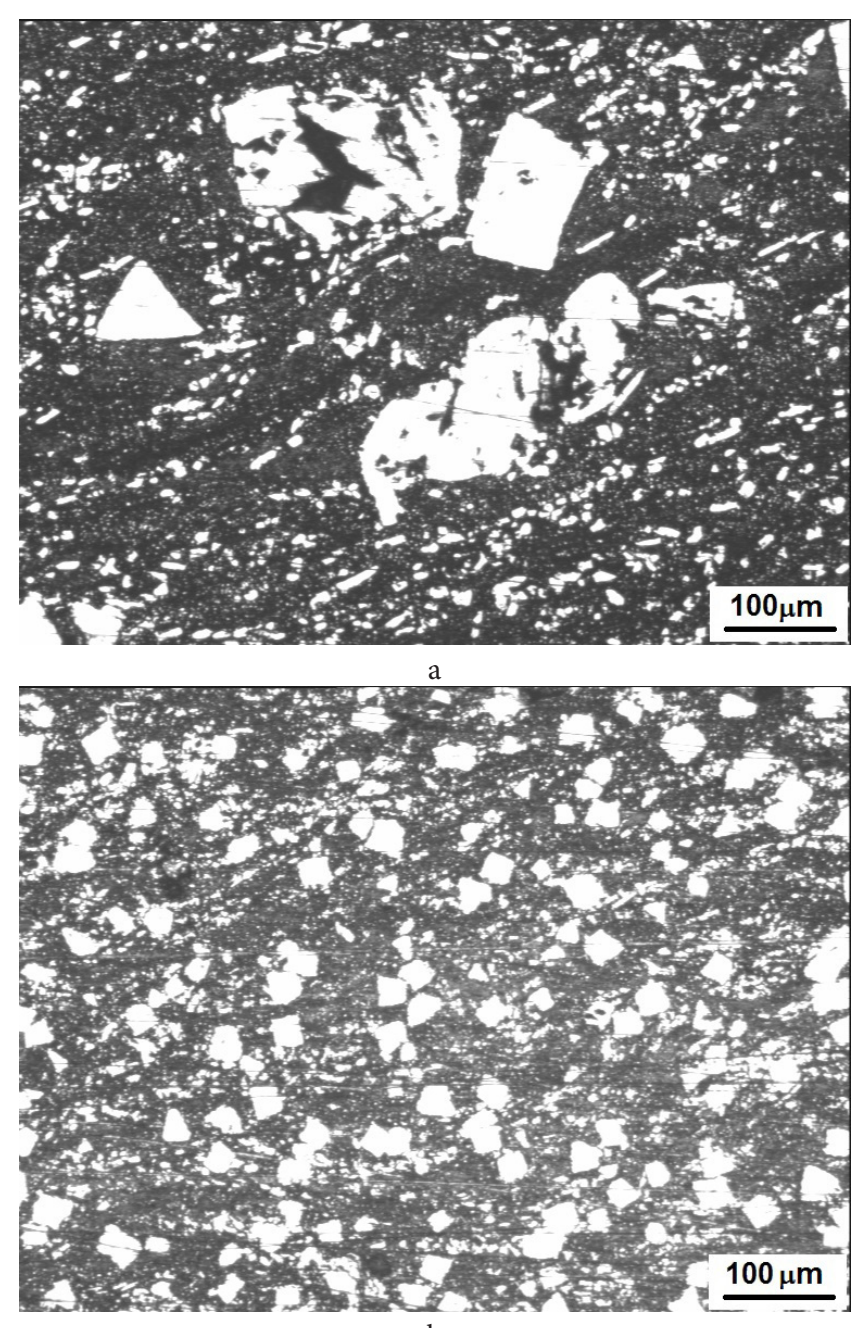

b

Fig. 2. Microstructure of the Sn11Sb5.5Cu Babbitt subjected to ECAP in states $I(\mathrm{a})$ and $I I(\mathrm{~b})$. the fast cooling, become disjointed, and the particles of both phases acquire a stitch-like arrangement (Fig. 2b).

The dependence of the wear of the Babbitt produced by conventional crystallization has two clearly distinguished stages (Fig. 3). At the first stage - the stage of running-in (path up to $600 \mathrm{~m}$ ), the wear rate is $0.0167 \mathrm{mg} / \mathrm{m}$, then it gradually decreases and by the end of the running-in stage it equals $0.0096 \mathrm{mg} / \mathrm{m}$. During further testing, the wear rate does not change.

The wear of the samples in state II demonstrates that the uniform distribution of intermetallic particles in the matrix phase formed during crystallization leads to the absence of the running-in stage (Fig. 3). Wear proceeds with the same rate in the whole test distance, equal to $0.0009 \mathrm{mg} / \mathrm{m}$.

The dependencies of the wear of the ECAP-processed samples have a similar character. Their two stages can be distinguished (Fig. 3). The running-in stage continues approximately up to $300 \mathrm{~m}$, and the wear rate is $0.008 \mathrm{mg} / \mathrm{m}$ for both states. Then the wear rate decreases down to $0.0037 \mathrm{mg} / \mathrm{m}$ for state $I$ and down to $0.0023 \mathrm{mg} / \mathrm{m}$ for state $I I$.

It can be seen that the ECAP processing of the Sn11Sb5.5Cu Babbitt rod in state $I$ leads to a considerable decrease in wear rate, whereas for the material in state II wear becomes more intensive. A possible explanation of this behavior is as follows. It can be rightfully assumed that severe plastic deformation not only results in the refinement of the particles of intermetallic phases, but also weakens their adhesive bond with the matrix. The brittle particles of the $\beta$ - and $\eta$-phases start to separate easily from the friction surface of the Babbitt in the process of wear. In the case of large particles, a positive effect from the decrease in the size of the separating particles dominates over the increase in their quantity as a result of the weakening of the adhestive bond. In contrast, in the case of small particles in the initial state, the weakening of adhesion leads to wear intensification as a result of separation of many particles.

The microhardness measurement data for the Babbitt in states $I$ and $I I$ before and after ECAP processing, presented in the Table 1, allow for another assumption about the origin of the change in the wear pattern. For the sample with large particles, the microhardness of the particles and the alloy's matrix amounts to 1050 and $190 \mathrm{MPa}$, respectively. In the Babbitt subjected to fast crystallization, the refinement of the $\beta$-phase particles down to $40-50 \mu \mathrm{m}$ and significant strengthening take place. The microhardness of the $\alpha$-phase increases approximately by a factor of 2.5 (up to $468 \mathrm{MPa}$ ), and the microhardness of the $\beta$-phase grows approximately by $10 \%$ as compared with the as-cast Babbitt (up to $1133 \mathrm{MPa}$ ).

Table 1. Microhardness of the alloy in different states.

\begin{tabular}{|c|c|c|c|}
\hline \multirow{2}{*}{$\begin{array}{c}\text { States of the } \\
\text { Sn11Sb5.5Cu Babbitt }\end{array}$} & \multicolumn{2}{|c|}{ Microhardness, MPa } & \multirow{2}{*}{$\mathrm{HV}_{\beta} / \mathrm{HV}_{\alpha}$} \\
\cline { 2 - 3 } & $\alpha$-phase & $\beta$-phase & \\
\hline State $I$ & 190 & 1050 & 11.67 \\
\hline State $I I$ & 468 & 1133 & 2.42 \\
\hline State $I$ after ECAP & 176 & 881 & 5.05 \\
\hline State $I I$ after ECAP & 185 & 634 & 3.43 \\
\hline
\end{tabular}




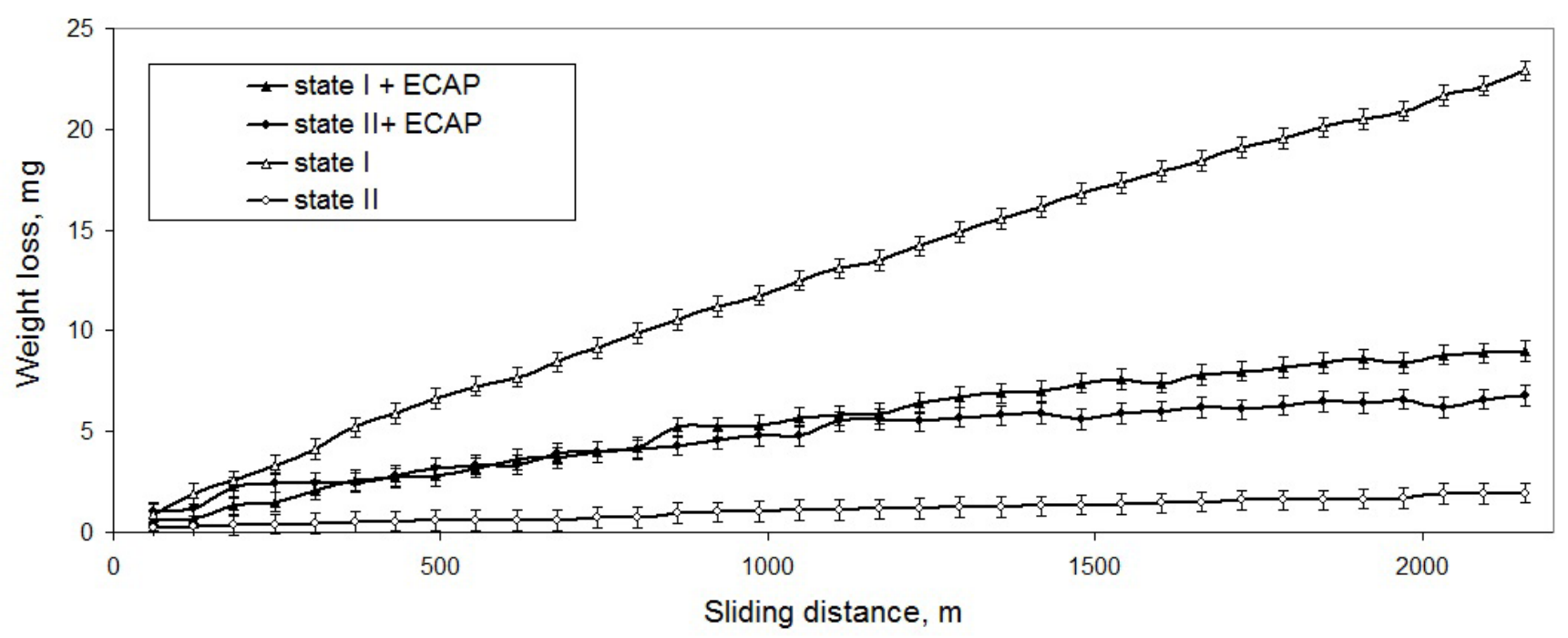

Fig. 3. Wear curves of the Sn11Sb5.5Cu Babbitt before and after ECAP.

That is why this state is characterized by the lowest wear rate since it fully complies with the Charpy rule: it contains a rather strong and ductile matrix, as well as solid particles that are able to create a strong frame. After ECAP processing, in both cases the softening of both the matrix phase and the intermetallic particles takes place. The microhardness of the $\alpha$-phase in the sample in state $I$ is reduced by $10 \%$, and that of the $\beta$-phase - by $20 \%$. In the sample in state $I I$, there occurs a sharp decrease in the microhardness of the $\alpha$-phase (by a factor of about 2.5) and of the $\beta$-phase (by a factor of 1.8).

When comparing the wear curves (Fig. 3 ) and the ratio between the microhardnesses of the matrix $\alpha$-phase and the $\beta$-phase particles (see the Table 1), it can be seen that the lowest wear is observed when the microhardness values have the least difference.

Thus, SPD processing is not an efficient method for improving the tribilogical characteristics of the $\mathrm{Sn} 11 \mathrm{Sb} 5.5 \mathrm{Cu}$ Babbitt. ECAP processing leads to a decrease in wear rate in the case of the as-cast Babbitt, having large intermetallic particle in its structure, due to their refinement. In contrast, in the case of an initial structure with small intermetallic particles, the tribological characteristics decrease due to the softening of phases and the degradation of the bond between the intermetallic particles and the matrix. Methods producing in the $\mathrm{Sn} 11 \mathrm{Sb} 5.5 \mathrm{Cu}$ Babbitt a structure with small intermetallic particles, based on the variation of the crystallization rate during casting, such as liquid forging, centrifugal casting, etc., appear to be more efficient and less costly.

\section{Conclusions}

The severe plastic deformation of the Sn11Sb5.5Cu Babbitt by equal-channel angular pressing leads to the dispersion of the particles of intermetallic phases and the weakening of their adhesive bond with the matrix. In the case of large particles of the $\beta$-phase produced by conventional crystallization, their refinement and softening causes a decrease in wear. In the case of small particles produced under a higher crystallization rate, the weakening of the adhesion to the matrix and a considerable softening of the matrix phase and the $\beta$-phase particles causes wear intensification. The use of ECAP processing for improving the tribological properties of Babbitt alloys by means of the refinement of their structure is inefficient.

Acknowledgements. The present work was performed in the framework of the state assignment of IMSP RAS (Reg. No. AAAA-A17-117041310218-5).

\section{References}

1. A. I. Shpagin. Antifrictional alloys. Moscow, Metallurgiya (1956) 326 p. (in Russian)

2. Ed. Yu. M. Vinogradov. Wear-resistant materials in chemical engineering. Handbook. Leningrads, Mashinostroyenie (1977) 256 p. (in Russian)

3. F. A. Sadykov, N. P. Barykin, I. Sh. Valeev, V. N. Danilenko. Journal of Materials Engineering and Performance. 12, 29 (2003).

4. I. M. Lyubarskii, L.S. Palatnik. Metal physics of friction. Moscow, Metallurgy (1976) 176 p. (in Russian)

5. A. Upadhyaya, N. S. Mishra, N. Ojha. J. Mat. Sci. 32, 3227 (1997).

6. A. Sato, R. Mehrablan. Met. Trans. B. 7B, 443 (1976).

7. L.G. Korshunov, N.I. Noskova, A.V. Korznikov, N.L. Chernenko, N.F. Vil'danova. The Physics of Metals and Metallography. 108, 519 (2009).

8. N. I. Noskova, L. G. Korshunov, A. V. Korznikov. Metal Science and Heat Treatment. 50, 593 (2008).

9. F. A. Sadykov, N.P. Barykin, I.Sh. Valeev. Strength of Materials, 34(2), 196 (2002).

10. N.P. Barykin, R.F. Fazlyahmetov, A.Kh. Valeeva. Metal Science and Heat Treatment. 48, 88 (2006).

11. A.Kh. Valeeva, I.Sh. Valeev, R.F. Fazlyakhmetov, A. I. Pshenichnyuk. Letters on Materials. 5(2), 147 (2015). (in Russian) DOI: 10.22226/2410-3535-2015-2-147-151

12. A. Kh. Valeeva, I.Sh. Valeev, R. F. Fazlyahmetov. Journal of Friction and Wear. 35(4), 311 (2014).

13. A.Kh. Valeeva, I.Sh. Valeev, R.F. Fazlyakhmetov, 
A.I. Pshenichnyuk. The Physics of Metals and Metallography. 116, 509 (2015).

14. A. Kh. Valeeva, I. Sh. Valeev, R. F. Fazlyakhmetov. Journal of Friction and Wear. 38(1), 53 (2017).

15. N. I. Noskova, R. R. Muluykov. Submicrocrystalline and nanocrystalline metals and alloys. The Ural Branch of the Russian Academy of Sciences, Yekaterinburg (2003) 279 p. (in Russian)

16. A.P. Zhilyaev, A.I. Pshenichnyuk. Superplasticity and grain boundaries in ultrafine-grained materials. Moscow, FIZMATLIT (2008) 320 p. (in Russian)

17. A.P. Zhilyaev, T. G. Langdon. Prog. Mater. Sci. 53, 893 (2008). DOI: 10.1016/j.pmatsci.2008.03.002

18. M. Markushev, E. Avtokratova, O. Sitdikov. Letters on
Materials. 7(4), 459 (2017). DOI: 10.22226/2410-3535-2 $017-4-459-464$

19. A. Kh. Valeeva, I. Sh. Valeev, R. R. Mulyukov, R. Khisamov. Letters on Materials, 6(4), 347 (2016) (in Russian) DOI: $10.22226 / 2410-3535-2016-4-347-349$

20. I.Sh. Valeev, A.Kh. Valeeva, A.Kh. Akhunova. Letters on Materials 7(3), 292 (2017). (in Russian) DOI: 10.22226/2410-3535-2017-3-292-295

21. V. L. Kolmogorov. Mechanics of metal forming: a textbook for higher education institutions. $2^{\text {nd }}$ ed. Yekaterinburg, Publishing House of the USTU-UPI (2001) 836 p. (in Russian) ISBN: 5-321-00050-6

22. V.S. Kovalenko. Metallographic reagents. Moscow, Metallurgiya (1981) 120 p. (in Russian) 